\title{
The Interplay between the Androgen Receptor, Soluble Factors and Tumour Microenvironment
}

\author{
Vikash Reebye ${ }^{1}$, Jeri Kim² ${ }^{2}$ Andrea Frilling ${ }^{1}$, Joanna P. Nicholls ${ }^{1}$, Nagy A. Habib ${ }^{1}$ and Paul J. Mintz ${ }^{1 *}$ \\ ${ }^{1}$ Department of Surgery and Cancer, Faculty of Medicine, Imperial College London, London, W12, ONN, UK \\ ${ }^{2}$ Department of Genitourinary Medical Oncology, MD Anderson Cancer Center, Unit 1374, 1515 Holcombe Blvd, Houston, TX 77030, USA
}

\begin{abstract}
Maintaining a balanced prostate microenvironment is pivotal for normal development and homeostasis of the prostate gland. This balance however is severely disrupted during the progression of prostate cancer where the local microenvironment becomes compromised. The cellular components associated with the microenvironment, including stromal cells, immune cells, blood vessels, and the extracellular matrix, interact cooperatively with prostate cancer cells through paracrine and autocrine actions of soluble growth factors and cytokines thus creating a modified tumour microenvironment. Understanding how paracrine and autocrine factors interact in this microenvironment may lead to improved understanding of prostate cancer progression and to the development of drug combinations that might target both the primary and metastatic prostate cancer tumour microenvironments.
\end{abstract}

\section{Introduction}

The interplay between prostate epithelial cancer cells and the surrounding stromal tissue is vital for tumour progression and metastasis. Prostate cancer cells require a sustainable microenvironment to survive and continuously grow. In the early stages, this is dependent on androgens where prostate epithelial cells express high levels of the corresponding androgen receptor (AR). Once the AR is activated, a cell signalling cascade is triggered, leading to the necessary transactivation of prostate genes specific to tumor growth. Accordingly, androgen ablation therapy is the mainstay treatment for prostate cancer. This form of therapy however only provides shortterm success in patients particularly those with more advanced stages of the disease. Unfortunately, a very high number of patients treated for prostate cancer will eventually relapse as resistance to hormone treatment inevitably follows, culminating in castration-resistant disease. Several molecular mechanisms have been proposed to explain this process [1-3], but the precise events that contribute to this is still largely unknown. What is clear is that the tumor microenvironment, which includes normal stromal cells as well as transformed cells, plays a pivotal role in cancer progression, metastasis, and resistance to therapy. The survival and proliferation of primary or metastatic cancer cells is largely influenced by an intricate network of cell signaling within the tumour milieu; thus understanding the inner workings of this microenvironment remains essential in order for better and more targeted therapies to be developed. This review will identify important soluble growth factors and cytokines essential to the development of the prostate tumour microenvironment (local and metastatic), describing their functions, and highlighting their paracrine and autocrine actions on prostate cancer cells including their regulation of the androgen receptor (AR).

\section{The Primary Tumour Microenvironment}

The elements that are crucial for establishing a nourishing microenvironment within a primary prostate tumor site includes stromal cells, blood cells, stem cells, the extracellular matrix, and soluble factors. The array of growth factors and cytokines secreted by both the prostate epithelial cancer cells and stromal cells largely determines the fate of the disease. These soluble factors perform paracrine and autocrine functions in addition to behaving as chemoattractants in the microenvironment thus dramatically enhancing tumor growth and metastasis. This effect is further exacerbated by soluble factors which communicate bidirectionally (with both the cancer cells and the stromal cells), coordinating positive and negative feedback loops to create a continuous synergistic interaction between prostate cancer cells and the surrounding tissues. The androgen receptor (AR) is expressed in both normal and abnormal prostate epithelial cells. Upon ligand activation, the AR translocates into the nucleus to activate all the necessary genes responsible for normal functioning of the gland [4]. The normal prostate microenvironment consists of prostatic ducts, epithelial cells, stem cells, and neuroendocrine cells along with the stromal components including fibroblasts, vascular endothelial cells, nerve cells, immune cells, the extracellular matrix and soluble factors such as growth factors and cytokines. These components interact either directly or indirectly by secreting autocrine or paracrine signalling molecules [5]. During the progression of prostate cancer, the homeostatic interaction between these components becomes severely disorganized leading to aberrant cell growth. The natural progression of prostate cancer varies greatly and involves multifaceted pathologies such as increased sensitivity to androgens and non androgenic steroids; and ultimately progression towards steroid independent growth. The various histological changes observed reflect this dysfunction within the tumor microenvironment where the epithelial/stromal interaction is significantly compromised and altered, favoring not only tumor survival but also metastatic growth (Figure 1). Fibroblasts within the stromal tissue also contributes to this dysfunction through the production of growth factors, cytokines and matrix metalloproteases [6-8]. This ultimately increases cell proliferation to prime the tumour cells for metastasis to secondary sites. Soluble factors are pivotal components of the tumor microenvironment and key mediators in

*Corresponding author: Paul J. Mintz, Department of Surgery and Cancer, Faculty of Medicine, Imperial College London, London, W12 0NN, UK, E-mail: p.mintz@imperial.ac.uk

Received August 20, 2011; Accepted October 20, 2011; Published October 24 2011

Citation: Reebye V, Kim J, Frilling A, Nicholls JP, Habib NA, et al. (2011) The Interplay between the Androgen Receptor, Soluble Factors and Tumour Microenvironment. J Steroids Hormon Sci S2:002. doi:10.4172/2157-7536.S2-002

Copyright: ( 2011 Reebye V, et al. This is an open-access article distributed under the terms of the Creative Commons Attribution License, which permits unrestricted use, distribution, and reproduction in any medium, provided the original author and source are credited. 


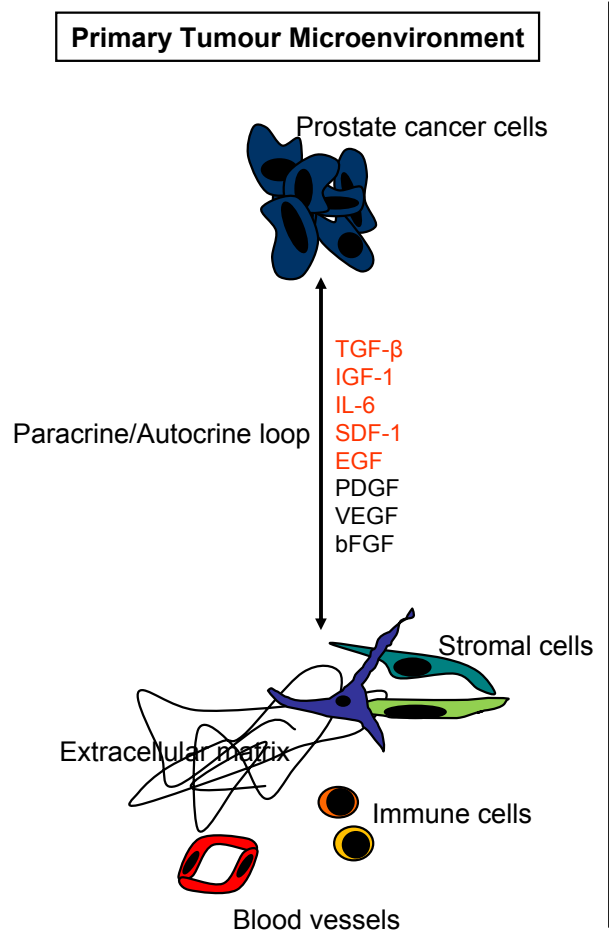

Figure 1: Primary tumour and and bone tumor microenvironments. Similar soluble growth factors and cytokines (highlighted in red colour) are used in the two different tumour microenvironments. tumor development and progression. These factors are secreted by many cell types including cancer cells to collectively have a profound effect on many biological functions such as proliferation, apoptosis, angiogenesis, differentiation, immune regulation, and survival. Because of their diverse biological roles, growth factors and cytokines have been excellent targets for developing novel therapeutic drugs against autoimmune disease and tumor growth.

In the early stages of prostate cancer, growth factors and cytokines that are secreted by the stroma greatly contribute to the severity and unpredictable behaviour of the disease by enhancing activity of the AR and ultimately increasing tumour mass [1,9-11]. Eventually, the presence of androgens no longer becomes a necessity to activate the $\mathrm{AR}$ as parallel signaling networks from the tumour microenvironment converge to support a hormone independent pathway involving MAPK (mitogenic activated protein kinase) and AKT (protein kinase B) amongst others $[1,11]$.

There are several important growth factors and cytokines essential to prostate cancer development, including epidermal growth factor (EGF), insulin-like growth factor-1 (IGF-1), stromal-derived factor-1 (SDF-1), interleukin 6 (IL-6), and transforming growth factor beta (TGF- $\beta$ ). Studies have demonstrated that these soluble factors are able to maintain AR activity in order to propagate cell survival and proliferation within the primary tumour microenvironment. This review will discuss how these factors contribute to communication across the tumour microenvironment [1,12-14]. Other important growth factors such as bFGF, PDGF and VEGF have been extensively reviewed elsewhere $[15,16]$. EGF is an abundant growth factor present in prostate tissue, where its primary function is in promoting cell proliferation and invasion $[17,18]$. A recent study showed that EGF could activate and phosphorylate the AR at key functional residues independent of hormone stimulation [19]. Moreover, in patients undergoing androgen ablation therapy, the expression level of the EGF receptor (EGFR) increases as castration-resistant prostate cancer develops. This observation suggests that EGF plays a crucial role within the primary tumor microenvironment where its production is amplified through both paracrine and autocrine pathways. This regulatory mechanism possibly promotes prostate tumour growth and expansion by maintaining activity of the AR even in the absence of androgen stimulation [20-23].

Another important growth factor involved in prostate cancer development is transforming growth factor $\beta$ (TGF- $\beta$ ). TGF- $\beta$ is part of a superfamily of secreted proteins of which the members include inhibins, activin, anti-müllerian hormone and bone morphogenetic protein. Expressed in normal as well as malignant prostate tissues [24], TGF- $\beta$ is highly conserved and is involved in multiple biological effects including angiogenesis [25], synthesis of components within the extracellular matrix [26], and immune T cell regulation [27]. Similar to EGF, TGF- $\beta$ also cross-talks with the AR axis to promote development of androgen independent cancer growth [28]. Since TGF- $\beta$ regulates cell cycle progression, apoptosis and modulation of immune $\mathrm{T}$ cells $[5,29,30]$ its expression levels could be indicative of the fate the local tumour mass might take. In addition to inducing angiogenesis TGF- $\beta$ also works with membrane metalloproteases and collagenase to induce tissue remodeling [4]. The overall effect thus involves enhanced TGF- $\beta$ levels and its accessory protein endoglin [31] within the prostate tumour microenvironment to maintain deregulated AR signalling in epithelial cells [28] and to facilitate tumour growth and metastasis to secondary sites $[29,32]$. Since the most common site of prostate cancer mestastasis is the skeleton, it is now recognized that TGF- $\beta$ also plays a strong part in promoting osteoblastic lesions. In vivo experiments with nude mice 
have demonstrated that targeted knockdown of TGF- $\beta$ significantly decreases osteoblastic bone formation and tumour incidence [33]. Since the prostate tumor microenvironment constantly changes during progression of the disease, these associated changes in autrocine and paracrine signalling are reflected by how cancer cells respond to this. Whilst EGFR signaling potentially enhances aberrant growth factor induced hormone-independent activation of the AR; TGF- $\beta$ is believed to contribute to prostate cancer induced bone metastasis.

In addition to TGF- $\beta$, stromal-derived factor 1 (SDF-1) also participates in facilitating bone metastasis. SDF-1 belongs to the chemokine family known as chemokine (C-X-X motif) ligand 12 or CXCL12. CXCL12 is known for is strong chemoattraction for lymphocytes during embryogenesis where it directs migration of hematopoietic cells from the foetal liver to the bone marrow for the formation of large blood vessels [34,35]. In adults, SDF-1/CXCL12 maintains a similar role in angiogenesis and this is observed in prostate cancer cell metastasis to the bone where CXCL12 initiates its signaling through the CXCR4 receptor to activate expression of alpha-v $\beta 3$ integrins (cell surface receptors that play a role in adhesion, migration, invasion, growth and angiogenesis) [36] and CD164 (an adhesive factor involved in haematopoiesis) [37]. This causes down regulation in the expression of the glycolytic enzyme phosphoglycerate kinase 1 (PGK1) and angiostatin in parallel to secretion of VEGF and tissue inhibitor of metalloproteases 2 (TIMP2) via the PI3K/Akt pathway [38]. Secretion of interleukin-6 (IL-6) and interleukin 8 (IL-8) is then initiated via the MAPK/Erk pathway to collectively promote growth of the cancer cells within the bone microenvironment [38]. The contribution of CXCL12 in this setting is highlighted when inhibition of its signalling almost completely stops the growth of prostate cancer in bone [39].

The cytokine interleukin-6 (IL-6) is an interesting molecule because of its diverse biological roles in many diseases. Its importance in cell proliferation, inhibition of apoptosis, inflammatory response, and osteoclast resorption of bone reflects the ubiquity of its expression in many tumor cells including prostate cancer [40-42]. Studies have shown that IL-6 can induce AR activity independent of androgens [43-45] where it is able to induce the AR to activate several androgen response promoters including PSA in the absence of steroidal hormones [43]. Since EGF, TGF- $\beta$ and CXCL12 appear to contribute towards regulation of IL-6 secretion within the tumor microenvironment $[46,47]$, a pattern of synergistic interaction between these factors and perhaps many more will eventually emerge to give us a better understanding of the key players involved in maintaining activity of the $\mathrm{AR}$ and promotion of tumour growth along a non-conventional signaling pathway.

Insulin-like growth factor-1 (IGF-1) is an endocrine hormone with similar molecular structure to insulin. Its primary action is mediated by binding to its receptor, the insulin like growth factor-1 receptor (IGF-1R), a receptor tyrosine kinase present on many cells that initiates intracellular signalling. Since IGF-1 is a strong activator of the Akt signaling pathway and an inhibitor of apoptosis, there are numerous studies being undertaken to elucidate the effects of inhibiting its signaling pathway for cancer therapy [48-53]. Epidemiological studies have established a link between high circulating serum IGF1 levels and the risk of developing advanced prostate cancer [50,54]. IGF-1 has been shown to stimulate proliferation of human prostate epithelial cell by enhancing activity of the AR [55,56]. Accordingly evidence also suggests that IGF-1R is highly expressed in prostate cancer cells [57-59] where it plays an important role in AR mediated progression towards androgen independent progression of the disease by compartmentalizing the AR into the nucleus [60]. Taken together, these numerous studies show that IGF-1 has an important functional role in AR signaling by potentiating the transcriptional activity of the $A R$ in the face of androgen ablation, through recruitment of coactivatiors and intracellular mediators such as the phosphoinositide 3-kinase (PI3K) signaling pathway. Collectively these signals invoke the action of other growth factors and cytokines from the primary and secondary tumour microenvironment for progression of the disease (Figure 1).

\section{The Bone Tumor Microenvironment}

Greater than $90 \%$ of patients with metastatic prostate cancer will have bone metastases [61-63]. In these cases, fractures, spinal cord compression, debilitating bone pain, and other severe bone complications result [61]. By secreting soluble factors that directly affect the function of osteoblasts and other important cellular and tissue components, prostate cancer cells can severely alter bone homeostasis and establish conditions favorable not only for cell survival but also for continuous cancer growth. Some of the growth factors and cytokines secreted by prostate cancer cells within the primary tumour microenvironment are able to remodel the bone tissue where the tight regulation of osteoclasts and osteoblasts operating under normal conditions undergoes severe disruption $[64,65]$. The important paracrine and autocrine factors that are involved with this include parathyroid-hormone-related peptide ( $\mathrm{PTHrP})$, prostaglandins, bone morphogenic proteins (BMPs), TGF- $\beta$, IGF-1, endothelin-1 (ET1) and IL-6 [66]. During alteration of the bone microenvironment, the propagation of these growth factors and cytokines attract other components including osteoblasts, osteoclasts, and stromal cells to facilitate angiogenesis and infiltration of the cancerous cells [67]. A major function of these growth factors is to stimulate osteoblasts to express RANKL, an important protein that regulates bone and stimulates growth factor secretion from osteoclasts. These secreted growth factors which include IL-6 and IGF-1 then stimulate prostate cancer cells to proliferate and expand from the primary tumour site, resulting in a perpetual cycle of interaction that creates a severely dysfunctional bone tumour microenvironment (Figure 1, Right Panel). Studies have shown that in bone metastases, osteoblasts can promote prostate cancer progression through cross-talk between prostate cancer epithelial cells and the various stromal components within the bone microenvironment $[68,69]$. Some of the secreted factors are unique to and more abundant in the bone, including PTHrP, BMPs, and ET-1. These factors play a central role in osteoblast development and bone infiltration of prostate cancer cells by stimulating prostate cell derived PTHrP to induce expression of nuclear factor- $\kappa \beta$ ligand (RANKL) [7072 ] and inhibit the expression of osteoprotegerin (OPG), which acts as a decoy receptor for osteoclasts [73]. This mechanism also explains why very high levels of PTHrP is observed in prostate cancer induced bone lesion sites $[74,75]$. The activation of RANKL on osteoblasts allows direct interaction with osteoclasts, which express its corresponding receptor RANK. This osteoblast-osteoclast interaction is then amplified by other soluble factors including IL- 6 and TGF- $\beta$ (both of which are also secreted by osteoclast cells), enabling continuous cross-talk with prostate cancer cells.

ET-1 is another important bone remodeling soluble factor secreted by prostate cancer cells to act as a mitogenic factor for osteoblasts at metastatic sites resulting in dysfunctional bone formation [76-78]. Interestingly, some of the gene targets of ET-1, including IL-6 and RANKL are also upregulated and collectively may perpetuate the synergistic interaction of TFG- $\beta$, IGF-1, IL-6, SDF-1/CXCL12, and EGF between the bone matrix and prostate cancer cells. 
Citation: Reebye V, Kim J, Frilling A, Nicholls JP, Habib NA, et al. (2011) The Interplay between the Androgen Receptor, Soluble Factors and Tumour Microenvironment. J Steroids Hormon Sci S2:002. doi:10.4172/2157-7536.S2-002

In summary, enhancing our understanding of the cooperative interaction between the stromal cells and cancer cells within the tumor microenvironment may lead to new therapeutic combinations of agents to disrupt them. It is evident that cancer cells are able to constantly interact and acquire adaptive and survival changes within the tumor microenvironment. Mechanistically, paracrine and autocrine actions of soluble factors released within this microenvironment are crucial in maintaining a perpetual interaction between the various cellular components of the surrounding tissues. Selectively targeting these growth factors and cytokines associated with the both the primary and secondary tumor microenvironment will undoubtedly produce better improved overall survival outcome for solid tumours such as prostate cancer.

\section{References}

1. Reebye V, Frilling A, Habib NA, Mintz PJ (2011)Intracellular adaptor molecules and AR signalling in the tumour microenvironment. Cell Signal 23: 1017-1021.

2. Feldman BJ, Feldman D, (2001) The development of androgen-independent prostate cancer. Nat Rev Cancer 1: 34-45.

3. Pienta KJ, Bradley D (2006) Mechanisms underlying the development of androgen-independent prostate cancer. Clin Cancer Res 12: 1665-1671.

4. Chung LW, Gleave ME, Hsieh JT, Hong SJ, Zhau HE (1991) Reciprocal mesenchymal-epithelial interaction affecting prostate tumour growth and hormonal responsiveness. Cancer Surv 11: 91-121.

5. Cunha GR, Donjacour AA, Cooke PS, Mee S, Bigsby RM, et al. (1987) The endocrinology and developmental biology of the prostate. Endocr Rev 8: 338362

6. Cunha GR, Ricke W, Thomson A, Marker PC, Risbridger G, et al. (2004) Hormonal, cellular, and molecular regulation of normal and neoplastic prostatic development. J Steroid Biochem Mol Biol 92: 221-236.

7. Camps JL, Chang SM, Hsu TC, Freeman MR, Hong SJ, et al. (1990) Fibroblastmediated acceleration of human epithelial tumor growth in vivo. Proc Natl Acad Sci U S A 87: 75-79.

8. Hu M, Yao J, Cai L, Bachman KE, van den Brûle F, et al. (2005) Distinct epigenetic changes in the stromal cells of breast cancers. Nat Genet 37: 899905

9. Culig Z (2004) Androgen receptor cross-talk with cell signalling pathways. Growth Factors 22: 179-184.

10. Efstathiou E, Logothetis CJ (2010) A new therapy paradigm for prostate cancer founded on clinical observations. Clin Cancer Res 16: 1100-1107.

11. Russell PJ, Bennett S, Stricker P (1998) Growth factor involvement in progression of prostate cancer. Clin Chem 44: 705-723

12. Taichman RS, Cooper C, Keller ET, Pienta KJ, Taichman NS, et al. (2002) Use of the stromal cell-derived factor-1/CXCR4 pathway in prostate cancer metastasis to bone. Cancer Res 62: 1832-1837.

13. Gaddipati JP, McLeod DG, Heidenberg HB, Sesterhenn IA, Finger MJ, et al. (1994) Frequent detection of codon 877 mutation in the androgen receptor gene in advanced prostate cancers. Cancer Res 54: 2861-2864.

14. Veldscholte J, Voorhorst-Ogink MM, Bolt-de Vries J, van Rooij HC, Trapman J, et al. (1990) Unusual specificity of the androgen receptor in the human prostate tumor cell line LNCaP: high affinity for progestagenic and estrogenic steroids. Biochim Biophys Acta 1052: 187-194.

15. van der Poel HG (2004) Smart drugs in prostate cancer. Eur Urol 45: 1-17.

16. Trojan L, Thomas D, Knoll T, Grobholz R, Alken P, et al. (2004) Expression of pro-angiogenic growth factors VEGF, EGF and bFGF and their topographical relation to neovascularisation in prostate cancer. Urol Res 32: 97-103.

17. Eaton CL, Davies P, Phillips ME (1988) Growth factor involvement and oncogene expression in prostatic tumours. J Steroid Biochem 30: 341-345.

18. Fiorelli G, De Bellis A, Longo A, Pioli P, Costantini A, et al. (1991) Growth factors in the human prostate. J Steroid Biochem Mol Biol 40: 199-205.

19. Guo Z, Dai B, Jiang T, Xu K, Xie Y, et al. (2006) Regulation of androgen receptor activity by tyrosine phosphorylation. Cancer Cell 10: $309-319$.
20. Hernes E, Fosså SD, Berner A, Otnes B, Nesland JM (2004) Expression of the epidermal growth factor receptor family in prostate carcinoma before and during androgen-independence. $\mathrm{Br} J$ Cancer 90: 449-454.

21. Cohen DW, Simak R, Fair WR, Melamed J, Scher HI, et al. (1994) Expression of transforming growth factor-alpha and the epidermal growth factor receptor in human prostate tissues. J Urol 152: 2120-2124.

22. Bonaccorsi L, Nosi D, Muratori M, Formigli L, Forti G, et al. (2007) Altered endocytosis of epidermal growth factor receptor in androgen receptor positive prostate cancer cell lines. J Mol Endocrinol 38: 51-66.

23. Léotoing L, Manin M, Monté D, Baron S, Communal Y, et al. (2007) Crosstalk between androgen receptor and epidermal growth factor receptor-signalling pathways: a molecular switch for epithelial cell differentiation. J Mol Endocrinol 39: 151-162.

24. Merz VW, Arnold AM, Studer UE (1994) Differential expression of transforming growth factor-beta 1 and beta 3 as well as c-fos mRNA in normal human prostate, benign prostatic hyperplasia and prostatic cancer. World J Urol 12 96-98.

25. Steiner MS, Anthony CT, Metts J, Moses HL (1995) Prostate cancer cells lose their sensitivity to TGFbetal growth inhibition with tumor progression. Uro Oncol 1: 252-262.

26. Roberts AB, Heine UI, Flanders KC, Sporn MB (1990) Transforming growth factor-beta. Major role in regulation of extracellular matrix. Ann N Y Acad Sci 580: 225-232.

27. McCartney-Francis N, Mizel D, Wong H, Wahl L, Wahl S (1990) TGF-beta regulates production of growth factors and TGF-beta by human peripheral blood monocytes. Growth Factors 4: 27-35.

28. Zhu ML, Partin JV, Bruckheimer EM, Strup SE, Kyprianou N (2008) TGFbeta signaling and androgen receptor status determine apoptotic cross-talk in human prostate cancer cells. Prostate 68: 287-295

29. Aihara M, Wheeler TM, Ohori M, Scardino PT (1994) Heterogeneity of prostate cancer in radical prostatectomy specimens. Urology 43: 60-66.

30. Lee C (1996) Role of androgen in prostate growth and regression: stromalepithelial interaction. Prostate Suppl 6: 52-56.

31. Romero D, O’Neill C, Terzic A, Contois L, Young K, et al. (2011) Endoglin regulates cancer-stromal cell interactions in prostate tumors. Cancer Res 71 3482-3493.

32. van den Ouden D, Tribukait B, Blom JH, Fossa SD, Kurth KH, et al. (1993) Schroder, Deoxyribonucleic acid ploidy of core biopsies and metastatic lymph nodes of prostate cancer patients: impact on time to progression. The European Organization for Research and Treatment of Cancer Genitourinary Group. J Urol 150: 400-406.

33. Mishra S, Tang Y, Wang L, deGraffenried L, Yeh IT, et al. (2011) Blockade of transforming growth factor-beta (TGFbeta) signaling inhibits osteoblastic tumorigenesis by a novel human prostate cancer cell line. Prostate 71: 1441 1454

34. Bleul CC, Fuhlbrigge RC, Casasnovas JM, Aiuti A, Springer TA (1996) A highly efficacious lymphocyte chemoattractant, stromal cell-derived factor 1 (SDF-1) J Exp Med 184: 1101-1109.

35. Askari AT, Unzek S, Popovic ZB, Goldman CK, Forudi F, et al. (2003) Effect of stromal-cell-derived factor 1 on stem-cell homing and tissue regeneration in ischaemic cardiomyopathy. Lancet 362: 697-703.

36. Sun YX, Fang M, Wang J, Cooper CR, Pienta KJ, et al. (2007) Expression and activation of alpha $v$ beta 3 integrins by SDF-1/CXC12 increases the aggressiveness of prostate cancer cells. Prostate $67: 61-73$.

37. Havens AM, Jung Y, Sun YX, Wang J, Shah RB, et al. (2006) The role of sialomucin CD164 (MGC-24v or endolyn) in prostate cancer metastasis. BMC Cancer 6: 195

38. Wang J, Wang J, Dai J, Jung Y, Wei CL, et al. (2007) A glycolytic mechanism regulating an angiogenic switch in prostate cancer. Cancer Res 67: 149-159.

39. Wang J, Shiozawa Y, Wang J, Wang Y, Jung Y, et al. (2008) The role of CXCR7/RDC1 as a chemokine receptor for CXCL12/SDF-1 in prostate cancer. J Biol Chem 283: 4283-4294.

40. Hirano T (1992) The biology of interleukin-6. Chem Immunol 51: 153-180.

41. Siegsmund MJ, Yamazaki H, Pastan I (1994) Interleukin 6 receptor mRNA in prostate carcinomas and benign prostate hyperplasia. J Urol 151: 1396- 1399. 
Citation: Reebye V, Kim J, Frilling A, Nicholls JP, Habib NA, et al. (2011) The Interplay between the Androgen Receptor, Soluble Factors and Tumour Microenvironment. J Steroids Hormon Sci S2:002. doi:10.4172/2157-7536.S2-002

42. Okamoto M, Lee C, Oyasu R (1997) Interleukin-6 as a paracrine and autocrine growth factor in human prostatic carcinoma cells in vitro. Cancer Res 57: 141146.

43. Lin DL, Whitney MC, Yao Z, Keller ET (2001) Interleukin-6 induces androgen responsiveness in prostate cancer cells through up-regulation of androgen receptor expression. Clin Cancer Res 7: 1773-1781.

44. Chen T, Wang LH, Farrar WL (2000) Interleukin 6 activates androgen receptormediated gene expression through a signal transducer and activator of transcription 3-dependent pathway in LNCaP prostate cancer cells. Cancer Res 60: 2132-2135.

45. Hobisch A, Eder IE, Putz T, Horninger W, Bartsch G, et al. (1998) Interleukin-6 regulates prostate-specific protein expression in prostate carcinoma cells by activation of the androgen receptor. Cancer Res 58: 4640-4645.

46. Aaronson DS, Muller M, Neves SR, Chung WC, Jayaram G, et al. (2007) An androgen-IL-6-Stat3 autocrine loop re-routes EGF signal in prostate cancer cells. Mol Cell Endocrinol 270: 50-56.

47. Park JI, Lee MG, Cho K, Park BJ, Chae KS, et al. (2003) Transforming growth factor-beta1 activates interleukin- 6 expression in prostate cancer cells through the synergistic collaboration of the Smad2, p38-NF-kappaB, JNK, and Ras signaling pathways. Oncogene 22: 4314-4332.

48. LeRoith D, Roberts CT (2003) The insulin-like growth factor system and cancer. Cancer Lett 195: 127-137.

49. Baserga $R$ (2005) The insulin-like growth factor-I receptor as a target for cancer therapy. Expert Opin Ther Targets 9: 753-768.

50. Pollak M, Beamer W, Zhang JC (1998) Insulin-like growth factors and prostate cancer. Cancer Metastasis Rev 17: 383-390.

51. Djavan B, Waldert M, Seitz C, Marberger M (2001) Insulin-like growth factors and prostate cancer. World J Urol 19: 225-233.

52. [Huang EC, Chen G, Baek SJ, McEntee MF, Collier JJ, et al. (2011) Zyflamend Reduces the Expression of Androgen Receptor in a Model of CastrateResistant Prostate Cancer. Nutr Cancer.

53. Ryan CJ, Zavodovskaya M, Youngren JF, Campbell M, Diamond M, et al (2008) Inhibitory effects of nordihydroguaiaretic acid (NDGA) on the IGF-1 receptor and androgen dependent growth of LAPC-4 prostate cancer cells. Prostate 68: 1232- 1240.

54. Wolk A, Mantzoros CS, Andersson SO, Bergström R, Signorello LB, et al. (1998) Insulin-like growth factor 1 and prostate cancer risk: a population-based, case-control study. J Natl Cancer Inst 90: 911-915.

55. Liu X, Choi RY, Jawad SM, Arnold JT (2011) Androgen-induced PSA expression requires not only activation of AR but also endogenous IGF-I or IGFI/ PI3K/Akt signaling in human prostate cancer epithelial cells. Prostate 71: 766- 777.

56. Culig Z, Hobisch A, Cronauer MV, Radmayr C, Trapman J, et al. (1994) Androgen receptor activation in prostatic tumor cell lines by insulin-like growth factor-I, keratinocyte growth factor, and epidermal growth factor. Cancer Res 54: $5474-5478$

57. Nickerson T, Chang F, Lorimer D, Smeekens SP, Sawyers CL, et al.(2001) In vivo progression of LAPC-9 and LNCaP prostate cancer models to androgen independence is associated with increased expression of insulin-like growth factor I (IGF-I) and IGF-I receptor (IGF-IR). Cancer Res 61: 6276-6280.

58. Plymate SR, Tennant MK, Culp SH, Woodke L, Marcelli M, et al. (2004) Androgen receptor (AR) expression in AR-negative prostate cancer cells results in differential effects of DHT and IGF-I on proliferation and AR activity between localized and metastatic tumors. Prostate 61: 276-290.
59. Pandini G, Mineo R, Frasca F, Roberts CT, Marcelli M, et al. (2005) Androgens up-regulate the insulin-like growth factor-I receptor in prostate cancer cells. Cancer Res 65: 1849-1857.

60. Wu JD, Haugk K, Woodke L, Nelson P, Coleman I, et al. (2006) Interaction of IGF signaling and the androgen receptor in prostate cancer progression. J Cell Biochem 99: 392-401.

61. R.E. Coleman (2001) Metastatic bone disease: clinical features, pathophysiology and treatment strategies. Cancer Treat Rev 27: 165-176.

62. Mundy GR (1997) Mechanisms of bone metastasis. Cancer 80: 1546-1556.

63. McMurtry CT, McMurtry JM (2003) Metastatic prostate cancer: complications and treatment. J Am Geriatr Soc 51: 1136-1142.

64. Ye L, Kynaston HG, Jiang WG (2007) Bone metastasis in prostate cancer: molecular and cellular mechanisms (Review). Int J Mol Med 20: 103- 111.

65. Logothetis CJ, Lin SH (2005) Osteoblasts in prostate cancer metastasis to bone. Nat Rev Cancer 5: 21-28.

66. Bussard KM, Gay CV, Mastro AM (2008) The bone microenvironment in metastasis; what is special about bone? Cancer Metastasis Rev 27: 41-55.

67. Tu SM, Lin SH (2008) Current trials using bone-targeting agents in prostate cancer. Cancer J 14: 35-39.

68. Logothetis CJ, Navone NM, Lin SH (2008) Understanding the biology of bone metastases: key to the effective treatment of prostate cancer. Clin Cancer Res 14: 1599-1602.

69. Chung LW, Huang WC, Sung SY, Wu D, Odero-Marah V, et al. (2006) Stromalepithelial interaction in prostate cancer progression. Clin Genitourin Cancer 5: 162-170

70. Cramer SD, Peehl DM, Edgar MG, Wong ST, Deftos LJ, et al. (1996) Parathyroid hormone--related protein (PTHrP) is an epidermal growth factorregulated secretory product of human prostatic epithelial cells. Prostate 29 : 20-29

71. Iwamura M, di Sant'Agnese PA, Wu G, Benning CM, Cockett AT, et al. (1993) Immunohistochemical localization of parathyroid hormone-related protein in human prostate cancer. Cancer Res 53: 1724-1726.

72. Iwamura M, Abrahamsson PA, Foss KA, Wu G, Cockett AT, et al. (1994) Parathyroid hormone-related protein: a potential autocrine growth regulator in human prostate cancer cell lines. Urology 43: 675-679.

73. Mundy GR (2002) Metastasis to bone: causes, consequences and therapeutic opportunities. Nat Rev Cancer 2: 584-593.

74. Bryden AA, Hoyland JA, Freemont AJ, Clarke NW, George NJ (2002) Parathyroid hormone related peptide and receptor expression in paired primary prostate cancer and bone metastases. $\mathrm{Br} \mathrm{J}$ Cancer 86: 322-325.

75. Deftos LJ, Barken I, Burton DW, Hoffman RM, Geller J (2005) Direct evidence that PTHrP expression promotes prostate cancer progression in bone. Biochem Biophys Res Commun 327: 468-472.

76. Nelson JB, Hedican SP, George DJ, Reddi AH, Piantadosi S, et al. (1995) Identification of endothelin-1 in the pathophysiology of metastatic adenocarcinoma of the prostate. Nat Med 1: 944-949.

77. Takuwa Y, Masaki T, Yamashita K (1990) The effects of the endothelin family peptides on cultured osteoblastic cells from rat calvariae. Biochem Biophys Res Commun 170: 998-1005.

78. Yin JJ, Mohammad KS, Käkönen SM, Harris S, Wu-Wong JR, et al. (2003) A causal role for endothelin-1 in the pathogenesis of osteoblastic bone metastases. Proc Natl Acad Sci U S A 100: 10954-10959.
This article was originally published in a special issue, Androgen Receptors handled by Editor(s). Dr. Rebecca L Cunningham, University of North Texas Health Science Center, USA; Dr. Ze-hua Liu, Osaka City University, Japan 